\title{
Analysis and Research on Development Trend of High-end CNC Grinding Machine
}

\author{
Ling Tianbai, He Yongyi
}

School of Mechatronic Engineering and Automation, Shanghai University, Shanghai 200072, China

lingtianbai998@sina.com

Keywords: High-end CNC grinding machine; machine tool control technology; development trend; compounding.

\begin{abstract}
. processing problem of complex and precise parts with small batch and many varieties can be solved by CNC grinding machine. It belongs to flexible and highly efficient automation machine tool, which represents the development direction of modern machine tool control technology. CNC grinding machine is a typical mechatronic product. Function specialization of CNC machine tool not only improves the productivity of the machine tool itself, but also greatly increases the production efficiency of all industries applying the special tool. It has especially prominent performance in automotive industry, and bottleneck of specialized production equipment has been prominent with acceleration of product updating speed and rapid diversification of social labor division. Flexible automation ability of CNC machine tool is greatly enhanced especially with the development of numerical control technology and performance improvement. Meanwhile, specialized demand on product is highly increased in all fields, more and more machine tool designs are deeply developed to the direction of flexibility. The machining efficiency of the machine tool has been largely beyond the specialization with continuous development of high speed and high precision technology. Integration of flexibility with high speed, high precision, intelligence, networking and modularization in concept level becomes important foundation of modern compound concept. Therefore compounding has become development direction of machine tool with realistic significance.
\end{abstract}

\section{Development of grinding machine cutting speed to ultra-high speed}

Ultra-high speed grinding usually refers to high-speed grinding with speed higher than ordinary grinding speed by more than five times (i.e. Vs $\geq 150 \mathrm{~m} / \mathrm{s}$ ). It was proposed by Salomon from German in 1931. Its English name is super-high speed grinding or ultra - high speed grinding. Ultra-high speed grinding mainly has the following characteristics basically: (1) grinding efficiency is high, and feeding speed can be correspondingly improved due to grinding speed improvement, therefore significantly improving the grinding efficiency. (2) The processing quality is high, ultra-high speed grinding has higher machining precision, lower grinding surface roughness and better machining surface integrity compared with ordinary grinding. (3) Material consumption is low. It can prolong the service life of the grinding wheel and reduce waste of cooling fluid. (4) Application scope of grinding process is expanded. Good grinding effect is obtained on hard brittle materials, high plasticity materials and materials which are difficult to grind. Ultra-high speed grinding can become the most important part in grinding development due to the characteristics.

Present situation and development of foreign high-speed grinding technology

In recent years, high speed grinding technology is also greatly developed, which is mainly manifested in the following two aspects:

(1) High speed grinding mechanism: because synthetic diamond and cubic boron nitride are greatly applied in grinding wheel manufacturing. High speed grinding is developed again, and ultra-high speed grinding with linear velocity 5 to 6 times and even higher compared with that of ordinary grinding.

(2) Grinding speed: High speed grinding technology has been developed rapidly in Germany. Its research results promote high speed grinding technology to a higher level. German DAPP Company 
produces high speed slow feed grinding machine with spindle rotation speed of $104 \mathrm{r} / \mathrm{min}$. Grinding wheel linear velocity is $250 \mathrm{~m} / \mathrm{s}$; Germany Aachen University is actively researching on $500 \mathrm{~m} / \mathrm{s}$ ultra-high speed grinding.

\section{Present situation and development of domestic high speed grinding technology}

Research on high speed grinding technology was started late in China, which has greater gap from foreign level. All high-speed grinding achievements are not product-based. In 2003, Northeastern University firstly developed the first ultra-high speed test grinding machine with rotational speed of $200 \mathrm{~m} / \mathrm{s}$, rated power of 55kw and the highest wheel linear velocity of $250 \mathrm{~m} / \mathrm{s}$ successfully in China. Hunan University started high speed and ultra-high speed research on a $250 \mathrm{~m} / \mathrm{s}$ ultra-high speed grinding machine spindle system since 2002. Maglev bearing design was firstly implemented in China. MKG1320 ultra-high speed CNC cylindrical grinding machine was developed in 2009, which was suitable for processing specific material parts in aviation, national defense and other industries. The equipment is provided with grinding wheel with diameter of $500 \mathrm{~mm}$ and linear velocity of 150 m/s. Shanghai Machine Tool Plant exhibited MGKS1332/H CNC high-precision high-speed cylindrical grinding machine on China International Industry Fair in 2010. The grinding machine linear speed is up to $150 \mathrm{~m} / \mathrm{s}$. The maximum grinding diameter is $\Phi 320 \mathrm{~mm}$. The maximum grinding length is $1000 \mathrm{~mm}$. The machine tool is mainly used for high-precision machining of super-hard materials, heat resistant alloy, composite materials and other novel materials which can not be processed by traditional machining methods.

Ultra-high speed grinding is characterized by high efficiency, high machining precision and wide machining range. It belongs to cutting-edge technology in advanced manufacturing technology. The ultra-high speed grinding machine can embody practical ultra-high speed grinding, which acts as ultimate goal thereof. Vigorous research, promotion and application of various novel ultra-high speed grinding machines have important significance to improve processing level of machinery manufacturing industry in China.

\section{Development of grinding machine cutting precision to direction of ultra-precision}

Grinding is a main method for precision machining and ultra-precision machining. It is generally divided into ordinary grinding, precision grinding and ultra-precision grinding. It has different precision scopes in different stages of production development. Currently, ordinary grinding generally refers to processing method for processing materials with surface roughness of Ra0.04 $1.25 \mu \mathrm{m}$, and the machining precision is greater than $1 \mu \mathrm{m}$; Precision grinding can achieve the surface roughness of $\mathrm{Ra} 0.16 \sim 0.16 \mu \mathrm{m}$ generally at present, and the machining precision is up to $0.5 \sim 1 \mu \mathrm{m}$. Ultra-precision grinding is a grinding method which can reach the lowest grinding surface roughness value and the highest processing precision at present, wherein surface roughness can reach $\leq \mathrm{Ra} 0.01 \mu \mathrm{m}$, and precision can be up to $0.01 \mu \mathrm{m}$ or even nano-scale.

\section{Development of foreign ultra-precision grinding machine and grinding technology}

Precision grinding machine is the foundation of precision grinding processing. High precision, integration and automation are development direction of precision grinding machine technology at present.

CUPE is a company engaged in developing ultra-precision grinding machine tools early. The company successfully developed OAGM2500 ultra-precision grinding machine, which is the largest ultra-precision grinding processing equipment at present, which is mainly used for ultra-precision grinding of hard brittle materials, such as optical glass, etc. Nano machining center produced by CUPE is provided with grinding head for ultra-precision grinding. The shape precision of machining work-piece can be up to $0.1 \mu \mathrm{m}$. The surface roughness is $\mathrm{Ra}<10 \times 10^{-3} \mu \mathrm{m}$.

The U.S. Moore Nanotechnology System Company produces ultra-precision grinding machine, wherein ultra-precision hydrostatic guide-way is adopted for keeping straightness of $0.3 \mu \mathrm{m}$, processing geometric precision of $0.1 \mu \mathrm{m}$ and surface roughness Ra5 $\times 10-3 \mu \mathrm{m}$. The U.S. LLNL Laboratory developed next generation ultra-precision optical processing equipment 2006 POGAL (Optic the Grinder and Lathe) in order to satisfy ultra-precision grinding demands of larger aperture 
optical components and hard brittle materials. The technology index of spindle axial direction and radial precision is $0.05 \mu \mathrm{m}$.

\section{Development of domestic ultra-precision grinding machine and grinding technology}

Chinese study on precision grinding is still in the initial stage, which is mainly concentrated in colleges and universities. ELID research group in Harbin Institute of Technology, led by Professor Yuan Zhejun, successfully developed pulse power supply, grinding fluid and grinding wheel for ELID grinding. Planar, cylindrical and inner circle ELID grinding devices are developed on domestic machine tool. Precision mirror surface grinding of various refractory materials is realized. Currently, the technology is actively promoted and popularized, thereby realizing product-based technology.

Researchers from Shanghai Donghua University School of Mechanical Engineering adopt consolidation grit low frequency vibration (frequency of $0.5 \sim 20 \mathrm{~Hz}$ and amplitude of $0.5 \sim 3 \mathrm{~mm}$ ). Appropriate economic processing conditions and relevant parameters are studied for pressure feed finishing machining. Ceramic work-pieces after abrasive machining are verified. The surface roughness thereof can be further lowered through ultra-precision machining, which can be degraded by $2 \sim 4$ grades. Tsinghua University deeply studied in the aspects of integrated circuit ultra-precision machining equipment, disk machining and ultra-precision abrasive belt grinding, diamond micro-powder grinding wheel ultra-precision grinding, etc. Corresponding products are produced.

\section{Development of grinding machine cutting mode to the direction of diversification and compounding}

Requirements on mechanical processing field are increased continuously with continuous development of all social fields. 'Three-high' processing with high speed, high precision and high efficiency is basic requirement on machining in the future. It is difficult to satisfy traditional concept of machining. Compound grinding technology will become the development direction of abrasive grinding in the future.

Numerical control high precision compound grinding center is important and urgent finishing equipment of modern manufacturing system. It is important guarantee of machining precision in foreign manufacturing industry, which is referred to as 'machine tool in processing machine tool'. A lot of machining difficulties can be significantly solved in the fields of military industry, aviation, cutting tools, measuring tool, fixture, machine tool, etc. High precision and long life of parts as well as high efficiency of energy transfer should be ensured for processing high precision bush components in aircraft engine, aviation power transmission device and aviation fuel injection device especially. It has important research and practical value. At present, the equipment only can rely on import. Technical added value is very high, and the price is expensive. A large number of foreign exchange expenditures can be caused each year.

Present situation of diversified and compound development of foreign grinding machine

Foreign companies began to study compound grinding machine early in 1980s. Currently, Switzerland Studer and Kellenberger, Spain Danuobate, Italy Morala, Japan Toyota Machinery and other company in foreign countries have been provided with design and manufacturing ability of numerical control high precision compound grinding center after development for nearly 30 years. Wherein, Switzerland Studer Company and Kellenberger Company have excellent product quality and performance, and a lot of products are sold in China. Therefore, high-amount trade deficit is formed in the equipment field within the country. CNC compound grinding machine produced by the above-mentioned product is characterized by high flexibility, high precision and compound processing. Agile, flexible and compound grinding and machining with one-time clamping and multiple procedures can be realized. However, domestic machine tool industry is still in the initial stage of development in the field. There are no related mature products. Basic conditions of main parameters in foreign high-precision compound grinding center are shown in Table 1. Basic condition of structure performance in foreign high-precision compound grinding center is shown in Table 2. 
Table 1 Main parameter comparison of foreign compound grinding center

\begin{tabular}{llll}
\hline Manufacturer & Studer & Kellenberger & Morara \\
\hline Machine tool model & S40CNCx1600 & VARIA UR1-2-3 & MTL2000 \\
Central height/mm & 175 & $175(225)$ & 255 \\
Central distance/mm & 1600 & 1500 & 2000 \\
Maximum grinding diameter/mm & 340 & 340 & 500 \\
Maximum grinding length/mm & 1600 & 1500 & 1540 \\
Maximum load among tips/kg & $130 / 150$ & $150 / 250$ & $200 / 450$ \\
CNC System model & FANUC16i-TB & Heidenhain iTNC530 & SIEMENS840D \\
system CNC axis quantity & 4(X,Z,B,C) & 4(X,Z,B,C) & 4(X,Z,B,C) \\
\multicolumn{1}{c}{ Programming mode } & ReieaseD & operation Kellenberger & software UNIGRIND \\
& system & package & MORALAdix \\
\hline
\end{tabular}

Table 2 Main structure comparison of foreign compound grinding center

\begin{tabular}{|c|c|c|c|}
\hline Manufacturer & Studer & Kellenberger & Morara \\
\hline Overall layout & $\begin{array}{l}\text { Traditional } \\
\text { mobile }\end{array}$ & $\begin{array}{l}\text { Traditional } \\
\text { mobile }\end{array}$ & $\begin{array}{l}\text { Rear grinding carriage; } \\
\text { all-movable }\end{array}$ \\
\hline Z-axle drive & $\begin{array}{l}\text { Servo motor, ball screw, } \\
\text { linear scale }\end{array}$ & $\begin{array}{l}\text { Servo motor, ball screw, } \\
\text { linear scale }\end{array}$ & Linear motor, linear scale \\
\hline $\mathrm{X}$-axle drive & $\begin{array}{l}\text { Servo motor, ball screw, } \\
\text { linear scale }\end{array}$ & $\begin{array}{l}\text { Servo motor, ball screw, } \\
\text { linear scale }\end{array}$ & Linear motor, linear scale \\
\hline $\begin{array}{l}\text { Cylindrical grinding } \\
\text { wheel spindle }\end{array}$ & Rolling bearing, pulley drive & $\begin{array}{l}\text { Sliding bearing submitting } \\
\text { dynamic pressure, pulley } \\
\text { drive }\end{array}$ & Elect \\
\hline $\begin{array}{l}\text { Inner cycle grinding } \\
\text { wheel spindle }\end{array}$ & $\begin{array}{l}\text { Internal rolling bearing } \\
\text { Electric spindle }\end{array}$ & $\begin{array}{l}\text { Internal rolling bearing } \\
\text { Electric spindle }\end{array}$ & $\begin{array}{l}\text { Internal rolling bearing } \\
\text { Electric spindle }\end{array}$ \\
\hline $\begin{array}{l}\text { Worktable guide rail } \\
\text { and lubrication }\end{array}$ & $\begin{array}{l}\text { Traditional V-balanced } \\
\text { pressure slid guide and guide } \\
\text { surface injection }\end{array}$ & $\begin{array}{lr}\text { PM traffic } & \text { control } \\
\text { technology } & \text { hydrostatic } \\
\text { guide-way } & \end{array}$ & $\begin{array}{l}\text { High rigidity roller linear } \\
\text { guide }\end{array}$ \\
\hline
\end{tabular}

\section{Present situation of diversified and compound development of domestic grinding machine}

Domestic CNC compound grinding machine was started late compared with foreign country. The production quantity of similar machine tool is few at present. There is also gap in manufacturing level. Domestic CNC compound grinding machine has made considerable development since 2010. All grinding machine manufacturing enterprises start to develop compound grinding machines vigorously in China, thereby flourishing national equipment manufacturing industry. Domestic enterprises, such as Shanghai Machine Tool Plant, Hangzhou Machine Tool Group, Wuxi Machine Tool, Tianjin No. 2 Machine Tool Plant, Guilin Grinding Machine, Beijing No. 2 Machine Tool, etc. independently studied and developed compound machine tools.

Shanghai Machine Tool Plant Co., Ltd. developed a H405-BE CNC compound grinding machine as shown in figure 1 . Three grinding heads are adopted for grinding machine and compositely arranged on grinding wheel rack turret. Three grinding heads respectively include cylindrical grinding head, end surface cylindrical grinding head and inner circle grinding head. AC servo motor on the grinding wheel rack turret is used for driving rotation (axis B), dividing and positioning. Composite grinding function of grinding wheels in many forms is realized through axis $\mathrm{B}$. Grinding machine head frame spindle is driven by AC spindle motor for rotation, thereby realizing step-less adjustment and control of work-piece rotating speed. Grinding wheel rack feeding (axis B) and worktable movement (axis Z) are driven by AC servo motor. The grinding machine is provided with special measuring instrument for online measurement of work-piece outer diameter, axis positioning, automatic finishing of grinding wheel, compensation function, etc. Automatic cycle grinding functions of outer circle, end surface and inner hole are completed by numerical control system under primary clamping conditions. Multi-procedure flexible compound machining can be realized. The maximum machining diameter of the grinding machine is $630 \mathrm{~mm}$, the maximum machining length is 
$2000 \mathrm{~mm}$, and roundness of work-pieces machined by grinding machine is $0.002 \mathrm{~mm}$. The diameter consistency of longitudinal cross-section is $0.005 \mathrm{~mm}$.

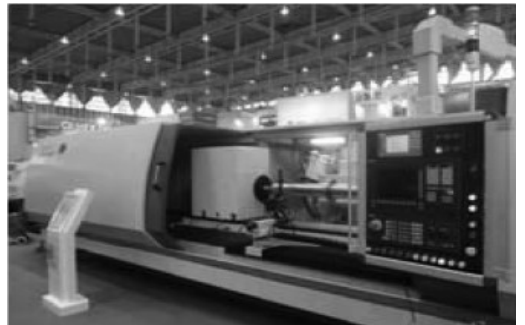

Fig.1 Appearance of H405 - BE CNC compound grinding machine

\section{Development of grinding machine cutting process to intelligent direction}

Machine tool cutting form is developed to the directions of diversification and compounding, grinding machine functions and structures are more and more complex. It has higher and higher requirements on intelligence in the cutting process control. It is mainly reflected in spindle vibration monitoring, movement interference, grinding wheel monitoring, dynamic balance and other aspects. Intelligence of the CNC machine tool requires that the machine tool should monitor itself in short, and physical quantity affecting machining precision and efficiency can be tested and modeled. Features are extracted. This is important foundation for realizing flexible automation and optimization. Internal state and external environment of machining system can be automatic perceived. Information and other factors related to machine tool machining state and environment are analyzed. Then, machine tool is controlled in real time through reasoning, decision-making, and adopting corresponding measures. Therefore, machining process of machine tool is in the optimum state. Table 3 shows CNC machine tool intelligence system which is product-based at present, functions thereof and corresponding mechanism.

In recent years, intelligent control technology of advanced manufacturing enterprises all over the world in the aspect of grinding machine is more and more mature, which have been applied widely. China grinding machine manufacturing enterprises just started the technology. They still have certain gap from technology of international advanced manufacturing enterprises. Currently, corresponding foreign products should be imported for intelligent modular systems for China grinding machine manufacturing enterprises.

Table 3 Intelligent systems of machine tool

Machine tool Intelligent system Function description manufacturer

Mazak Intelligent agenda Section chief can realize real-time precision operation scheduling on management system each machining station through agenda management, and idle time of machine tool can be maximally reduced.

Intelligent cutter Data is analyzed for tool of each device according to machining management system tasks. Machining tool demand and state can be improved.

Intelligent programming Part information is obtained from cadFigure paper, thereby management system preparing processing technology, procedure and route, configuring (Fig. 2) tool, etc.

Intelligent monitoring Daily equipment operation state in the plant can be fed back to pc of management system management personnel. Therefore, management personnel and corresponding department can comprehend implementation condition of machining site at any time.

Okuma Crash-proof intelligent Machine tools can not be collided during manual or automatic system (Figure 3) operation.

Thermal displacement of Transfer of machine tool body temperature is controlled in order to control plan reach thermal equilibrium state and reduce machining error.

Searching function of The machine tool spindle rotation speed can be adjusted to eliminate machining condition vibration of machine tool spindle, and therefore machine tool operation can reach the optimal state. 


\begin{tabular}{lll}
\hline Studer & $\begin{array}{l}\text { Grinding application The software package can be directly operation in the operating } \\
\text { software package }\end{array}$ & $\begin{array}{l}\text { system of machine tool. Drawing, procedure, process, rapid cutter } \\
\text { alignment and other short-cut functions can be modified directly in } \\
\text { the machine tool system. }\end{array}$ \\
\hline
\end{tabular}
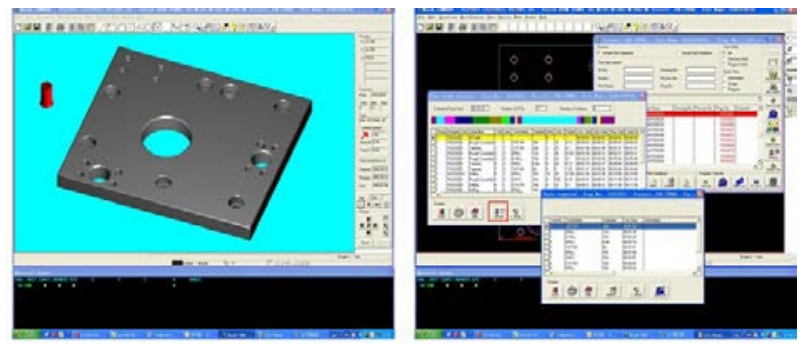

Fig. 2 Intelligent programming management system

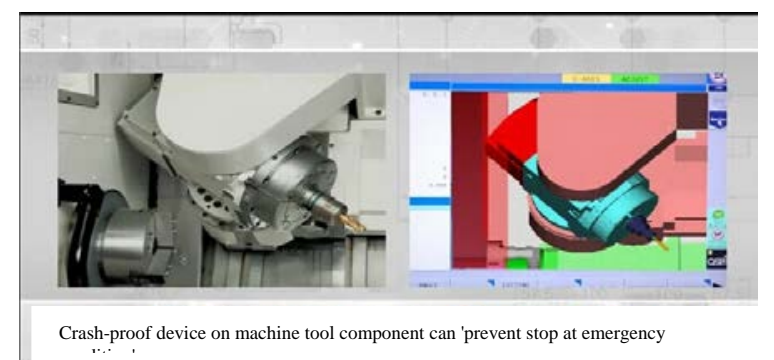

Fig. 3 Crash-proof intelligent system

\section{Conclusion}

Gap is discovered through comparison with world advanced machine tool manufacturing company. World advanced manufacturing process and technology can be actively traced. Technological innovation and product structure adjustment can be implemented according to market demand with fruitful results. Domestic advanced grinding machine manufacturing enterprises represented by Shanghai Machine Tool Plant Co., Ltd., etc. must catch the opportunities of major technology projects of national 'high-end CNC machine tool and basic manufacturing equipment'. They should vigorously carry out development transformation mode, and implement industrial structure adjustment and product upgrading constantly. Grinding machine manufacturing technology in China is fully exhibited, which is rapidly developed to high precision, high speed, high efficiency, compounding, flexible production line, intelligence and automation directions.

\section{References}

[1] Yao Jun. Review on CIMT2009 surface grinding machine and compound grinding machine exhibits , J. Precision Manufacturing and Automation, 2009, 2:1-6.

[2] Yao Jun. Overview of domestic and foreign CNC vertical compound grinding machines and development trend, J. Precision Manufacturing and Automation, 2008, 4:4-7.

[3] Huang Yun. Review of research present situation of grinding machine modularization, J. Machine Tool and Hydraulics 2010, 20 (3):139-140.

[4] Zhao Haibo, Du Hao, Wang Linlin. Review of research on grinding technology and grinding machine, J. Tool Technology, 2013, 47 (11): 12-14.

[5] Li Zhaofeng. On CNC machine tool development and development trend, J. Mechanical Equipment, 2013, 10 (18): 169. 
[6] Fang Minglun, Shen Nanyan, Li Jing, at el. Solution of core technology for accelerating to develop high-end grinding machine, J. Journal of Shanghai University (natural science edition), 2011, 4 (17): 379-390.

[7] Cai Guangqi, Feng Baofu, Zhao Henghua. The latest progress of grinding technology, J. World Manufacturing Technology and Equipment Market, 2003 (1): 16-19.

[8] Li Xiaozhong. Analysis on intelligent technology development trend of mechanical manufacturing, J. Technology and Enterprise, 2011, 23, (15): 16 -18.

[9] Feng Wei. Development situation of precision and ultra-precision grinding, J. Precision Manufacturing and Automation, 2009, (2): 7-9.

[10] Peng Hao. Present situation of development and research of CNC compound grinding technology, J. Aviation Manufacturing Technology, 2010, 10:54-57. 